\title{
NUEVAS APOSTILLAS DE LEXICOGRAFÍA HISPANOÁRABE (AL MARGEN DEL DICCIONARI ETIMOLOGIC I COMPLEMENTARI DE LA LLENGUA CATALANA DE JOAN COROMINES). II
}

\author{
Por \\ FEDERICO CORRIENTE
}

En los vols. IV y $V$ de esta grandiosa obra hemos encontradó pertinentes las siguientes observaciones:

forca: No nos parece posible que haya ninguna conexión entre esta voz y la que Coromines califica de árabe hispánico y magrebi (en realidad, clásica) /farqadāni/ (generalmente usado con artículo, y cuya traducción precisa es beta y gamma de la Osa Menor, según P. Kunitzsch, Untersuchungen zur Sternnomenklatur der Araber, Wiesbaden 1961 , p. 58 , de modo que el sentido de "Géminis" que les atribuye el Vocabulista será error o uso local, sobre lo que nada nos dice el mismo especialista en su obra Arabische Sternnamen in Europa. Wiesbaden 1959, pp. 192-3, al hablar de ambasl. Aunque aislada dentro del léxico árabe y, por consiguiente, susceptible de ser un préstamo en su sentido originario de "ternero", esta voz pertenece a la más antigua documentación de la lengua, siendo además lo normal en tecnicismos astronómicos que el préstamo lo haga el árabe a las lenguas europeas.

forfori: Convendría citar, a propósito de su étimo árabe el artículo de $\mathrm{P}$. Cunha Serra, "O "arrátel folforinho" " en Revista Portuguesa de História (Fac. de Letras, Univ. de Coimbra) 13(1970)139.

fris: No hay que dar mucha credibilidad a la etimología persa del Tāj al-ćArūs que intenta ver en el árabe./ifriz/ un reflejo de /parvaz/ (con las variantes /parvazl. /barvazl, /farvaz/, faraviz/ y /farviz/ en Vullers, que lo traduce por "limbus vestis" y le da la etimología /far $\alpha$ aviz/ ures dependens, pensilis"), pues dicha voz ha pasado a algunos dialectos neoárabes como /birwãz/ "marco, bastidor" (v. Dozy, Supplément, s. v.l, adoptando con ligerísimo cambio, en efecto, un esquema morfológico normal para el árabe, sin que nada haya hecho necesario un cambio tan complicado como el que habría producido /ifrīz/. En cuanto a aquella voz persa, sus muchas variedades ya acusan un posible préstamo o reintroducción; para /ifrīz/ hay que pensar en el gr. $\pi \varepsilon \rho i \zeta \omega \mu \alpha$ ucinturón" o derivado similar de $\pi \varepsilon \rho \iota \zeta \omega$ vu$\mu \alpha l$ "ceñirse", reflejado por siriaco /perizoma/ y /praizoma/ "faja» y talmúdico /prizomața/ "mandil», cuyo uso metafórico es obvio, aunque no esté documentado como tecnicismo arquitectónico. 
gabella: A propósito de mogobell, v. mogollón en las anteriores "Apostillas". gaiatell "boya»: Es probablemente un derivado con sufijo diminutivo romance del árabe /gāyalt)/ "bandera, estandarte" (en curiosa alternancia con su sinónimo /rāya/, que probablemente representa la original raíz $\left\{r^{\prime} y\right\}$ "ver», constituyendo un caso pre$\operatorname{coz}$ de $/ \mathrm{r} />\mid \bar{g} /$, característico de algunos dialectos neoárabes.

gairell: Al hacer la etimología de gaidó </gaydún/ es preferible recurrir al mașdar /gayd/ "achicamiento de agua" con el sufijo romance aumentativo/intensivo [-ón\}. gaitil «letrina»: Podría fácilmente derivar, como voz jergal, del árabe /gā'iț/ (andalusí Igáyț/ "excremento", con un sufijo romance, tal vez deformado de una forma hipotética */gayțáyrl, con disimilación.

garbell: Hemos señalado en las anteriores «Apostillas» el origen semítico del árabe Igirbāll, y el carácter casual de su similitud con crībellum.

garsó "Esqueje»: Derivará efectivamente de un hispanoárabe */garsún/, pero este final es debido al sufijo romance [-ón\}, pues esta voz no podía en ningún caso recibir el plural regular que, además, habría tenido la forma $\{-i ́ n\}$ en dialecto, nunca la clásica $\{-u ̈ n\}$.

gasi/ama y gatzim «convite, agasajo": no derivará de \{hzn\} "almacenar", lo que es semánticamente muy rebuscado, sino más probablemente de /"azímal "convite" (v. Dozy, Supplément, s. v.), siendo probable que gasama acuse contaminación con salama.

geneta "gineta»: Sugerimos como posible pista para aclarar la oscura etimología del nombre de este animal, tan temido por sus depredaciones, que se trate de un eufemismo "yerneta", paralelo a "comadreja". Esto explicaría el jarnayt de Dozy, que ha podido circular en al-Andalús con una pronunciación */jitrinéț/, apta para explicar castellano y catalán.

gratzem "planta que conté un granet i un pinyol típics»: su derivación como cruce de gra con un árabe vulgar gamzen (por mahzzan) debiera claramente indicar que se trata de una forma metatética hipotética, y añadiriamos improbable, pues lo es en todo el árabe, al constituir el prefijo \{ma-\} una marca de categoría derivacional.

gúa umedida de longitud de las embarcaciones»: Derivará probablemente del árabe $\mid k \bar{u}$ ' "codo".

llagut «laúd»: Ambas voces parecen acusar una pronunciación andalusí /cáwd/ con la diptongación señalada en nuestro Sketch 1.3.6.

llangardaix: No es totalmente exacto que /hird/dawn/ sea una voz aislada en árabe, ni hay que excluir la inexistencia de raíz semítica porque una voz haya quedado aislada y sin más representantes dentro de una raiz. En el caso que nos ocupa parece haber una conexión con \{hrd\} «irritarse», lo que puede ser semánticamente apropiado para algunas especies de lacértidos.

lleba "falleba": Una vez más, la intuición y experiencia de lingüista llevan a Coromines a una solución correcta, al suponer un */hallāba/árabe, por /mihlab/: efectivamente, en neoárabe es frecuente la formación de nombres de instrumento con la forma $\{1 a 22 \bar{a} 3 a\}$, en lugar de $\{$ mi12a3(a)\} o \{mi12ā3\}.

llebre: Es valiosa la observación de Coromines de que el "labbay" del Vocabulista podría ser, no el "lebrel» que supusimos en nuestro artículo en Vox Romanica 39, sino tal vez "(terreno) en que abundan las liebres".

lluquet: No derivará de un */wuqayd/ diminutivo, sino del propio /waqĩd(a)/, ya que de haberse formado el diminutivo de esta voz habríamos tenido */wuqáyyad/ en andalusf, "/wqíyyid/ en norteafricano: erraba Dozy al suponer aquel diminutivo $y$, en realidad tenemos el fenómeno $/ \# w a />/ u /(v$. Sketch 4.1 .8 , y piénsese en el mismo catalán algutzir), bien conocido en el norteafricano /uq/gĩd(a)l.

mafader "balsero", el que transporta los troncos a flote por el río»: No derivará de /mahadda/ "almohada", sino que se trata de una sufijación romance de /mahaạual 
"vado, lugar por donde se cruzà el río", ya que la función de estos hábiles operarios es llevar los troncos de uno a otro punto del río.

magarrufa "caricia frivola" (y portugués magarufa «mulher de mau porte): la etimología que propone Coromines a partir de \{g̈rf\} "sacar a cucharadas o con la mano" nos parece falta de apoyo en alguna juntura semántica árabe. Partiendo de la base que sugiere el portugués, más conservador en sus arabismos que cualquier otro romance ibérico, de que la voz se aplicara en primer lugar como adjetivo femenino, y que su primera connotación haya sido "mezquino; triste; murrioso», creemos puede tratarse de * mahrúfa "chocha, ida de la cabeza", participio no agentivo de la frecuentísima raíz $\{\underline{h} r f\}$, formación no atestiguada, pero que sabemos no era infrecuente en andalusí (v. Sketch 9.5.2e sobre participios no agentivos formados a verbos estativos, contra la norma clásica).

maimó "mono": v. maimón en las anteriores "Apostillas".

maissela o maixella "manojo de espliego que se quema en Navidad": con muchas reservas, sugerimos un étimo andalusi /mašcálal "antorcha». En cuanto al castellano jamila, v. anteriores «Apostillas", a lo que se puede añadir una propuesta con el diminutivo romance de $/ \mathrm{s̆am}^{\prime} /$ "cera».

mancús: Es ininteligible la afirmación sobre ad-dinâr al-manqû̉ de que "aquesta expressió, sencera, es troba realment en el vell poeta persa, en llengua aràbiga, Alí Al-Aghani (mort a lspahan el 971): ka-an wáğahahu ad-dīnâr al-manqûs»: lo que Dozy afirma, y así es, es que dicha expresión (que no es verso) se encuentra usada en el Kitāb al-Agānī (ed. Būlāq, X, p. 52, línea 10), donde las palabras / ka'anna wajhahu ddīnāru Imanqūs/ son atribuidas a 'Umar b. Abì Rabịa, poeta hijāzi demasiado conocido para necesitar presentación. El poeta persa de lengua árabe, muerto en 967 , no 971, sería en todo caso Abulfaraj al-Ișbahānī, recopilador de dicha obra, por lo que todos estos datos requieren corrección. En cuanto al reflejo /s/ de $/ \zeta /$ se debe seguramente a una transmisión por el bajo latín.

manyac "de condición suave, dócil; viciado, mimado»: esta voz catalana y occitana de difícil etimología podría derivar del árabe sirio manyak ubardaje» (v. A. Barthélemy, Dictionnaire Arabe-Francais. Dialectes de Syrie, Paris, Geuthner, 1935), de uso aún frecuente, y que podría haber penetrado durante las Cruzadas o por las relaciones comerciales.

marfanta: v. magaña en las anteriores «Apostillas».

marjal: Vilamarxant no puede contener el dual de /marj/ "pantano" en la forma /lbn/ o /binā' almarjāni/, pues sería /marjayn(i)/, tanto en clásico como en vulgar, con resultado vocálico /e/ en romance.

màrtava: en la cita de Averroes, sin ic räb, hay que enmendar aulan y garọ en lawwalan/ y /garaḍ/.

mesqui: No es cierto que el árabe /miskīn/derive de la raíz $\{s k n\}$ «apaciguarse, humillarse", ya que, a través del arameo, es un reflejo del acadio muškēnu(m) "pobre, miembro de la clase social perteneciente a palacion ( $v$. W. von Soden, Akkadisches Wörterbuch, s. v. y The Assyrian Dictionary de la Universidad de Chicago, s. v., con la bibliografía en ellos contenidal.

mesquita: v. mezquita en las anteriores "Apostillas".

moraga: $v$. moraga en las anteriores "Apostillas".

nafrar y nafra: Derivarán seguramente de nahr(a) "degolladura".

necla: Es muy dudosa su derivación de una raíz árabe $\{n q l\}$, e imposible derivar năqala de naqāla.

nissaga "estirpe, casta" bien podria derivar del árabe /nisāja/ "contextura", recogido por Dozy en su Supplément. Sería, posiblemente, préstamo tardío, producido por el comercio en las escalas de Levante, y no a las relaciones con al-Andalús. 